\title{
Enterprise Solutions Criteria in the Age of GeoBlockchain: Land Ownership and Supply Chain
}

\author{
Constantinos Papantoniou \\ Claremont Graduate University \\ constantinos.papantoniou@cgu.edu \\ cpapantoniou@esri.com
}

\author{
Brian Hilton, Ph.D. \\ Claremont Graduate University \\ brian.hilton@cgu.edu
}

\begin{abstract}
Land ownership and supply chain use cases are an enormous business challenge for both the public and private sectors. Every organization has different needs and wants, and industry leaders are researching and exploring ways to improve and impact their business transaction processes. Blockchain and Geospatial technologies are two tools that could help an organization add value in this manner. The combination of blockchain and geospatial technologies would result in the new concept of GeoBlockchain, defined here as a solution artifact that could be used to trace the trends and behaviors of participants (users) geographically and spatially, based on distributed nodes, transactions, and geo-locations via blockchain technology. The result of this research was the design, development, and implementation of two enterprise solution prototypes for land ownership and supply chains. This research indicates that blockchain technology can be integrated with geospatial technology, resulting in the GeoBlockchain implementation.
\end{abstract}

\section{Introduction}

Blockchain is a new promising technology that can provide trust, immutability, and transparency to any organization's systems of systems. The first proof-ofconcept using blockchain technology was cryptocurrency. This was later developed and implemented for public blockchains such as Ethereum and Bitcoin [33].

While unusual, this use case demonstrated that blockchain technology could orchestrate valid transactions across a distributed network and store those transactions in unalterable ledgers across multiple nodes $[23,24,28,32]$. Every new ledger transaction is a new block and all blocks construct the blockchain [27].

Today, we see considerable demand for enterprise technologies that could use private blockchains. The critical advantages of blockchain are the high speed of transactions, trust among participants, and valid accurate data [32]. The value of its use is the increase in trust and fast data collaboration among users while reducing the risk of fraud and the overall cost of monitoring goods and assets through the business chain lifecycle [7].

We are also beginning to observe a high demand for blockchain across both the private and public sectors that incorporate geographic information systems; specifically, land ownership and supply chain use cases. Geographic Information System (GIS) technology, an inherently location-based technology, can help answer the question of where a blockchain transaction has occurred [32].

The combination, and integration, of blockchain with GIS underlie the concept of GeoBlockchain. This new tool can be used to support the analysis of spatialtemporal trends of blockchain transactions via a geospatially-enabled blockchain [15]. But why do we need to integrate geospatial technology with blockchain technology? It has been suggested, that when designing a blockchain for real estate, it should provide a protocol that allows for a complete real estate transaction, which can offer at least the same guarantees for both the signatories and for third parties as current procedures. As such, this technology should meet the following criteria: 1) the permissioned blockchain should be controlled by public authorities, and 2) the blockchain should be linked to an official digital ID [12]. Related to supply chain technology, little is understood regarding the disruption blockchain adoption has had on transport and logistics, however, blockchain has the potential to be interlinked with a variety of transportation, logistics, and supply chain activities and methods that rely on organizational and process information [17]. Implicit in both use cases is the locational aspect of these activities. The solution designed, developed, and implemented as part of this study, explicitly includes location.

For this study, the design science research (DSR) methodology was used [18] while the Q Methodology [10] was utilized to investigate participant viewpoints of blockchain and geospatial technologies. Accordingly, the first task was to identify the main components for the GeoBlockchain implementation. For the second 
task, a list of metrics and criteria were created for the participants for a private blockchain and geographic information system scenario. The third task included the design, development, and implementation of two artifacts using the Hyperledger Fabric framework as the blockchain platform and ArcGIS Enterprise as a geospatial technology platform. The fourth, and final task, included the evaluation of the artifacts and documentation of the findings.

The outcome from these activities are two GeoBlockchain enterprise proof-of-concepts. The first, a web application for a land ownership, and the second, a web application for supply chain. Both solutions are the result from a co-simulation GeoBlockchain Enterprise framework activity [5].

\section{Literature Review}

Geographic Information Systems (GIS), also known as spatial information systems, are digital systems for collecting, storing, analyzing, and visualizing spatial data. GIS is a unique category of information system where the various spatial properties of data can be defined in space as points, lines, or polygons and that can be manipulated by a GIS system for spatial and non-spatial analyses [16].

GIS can be applied in many ways: urban planning, architecture, preservation of environment, cadaster, logistics, real estate, agriculture, and spatial planning [31]. GIS has the power to analyze and incorporate a variety of datasets in infinite ways; therefore, it can be advantageous for every industry from agriculture, utilities, real estate, land ownership and supply chain to implement spatial information systems [14].

On the other hand, when it comes to blockchain technologies, there are mixed views and attitudes from users due to the complexity of the technology, its maturity level, and unconventional initial usage that does not highlight the real value of blockchain. As was mentioned previously, the first implementations of blockchain were public implementations for cryptocurrencies.

Blockchain is a way to build trusted data in a distributed, unalterable ledger that records the history of immutable transactions. When a record is submitted to the blockchain it is stored in a distributed network system with multiple ledgers. Transparency and visibility among participants are valuable benefits while the risk of non-accurate data and the overall cost of legal procedures to validate the information could be minimized. Blockchain is a new method to share and collaborate using trusted data across distributed ledgers and computers. Every participant in the blockchain can validate any information at any time based on assigned rules and roles.
Some of the more promising applications for blockchain systems are cadaster-land ownership and supply chain. A Cadaster is detailed recording of land information in a real estate system, which has comprehensive legal documentation, including the dimensions, and precise location of land parcels [29]. Cadastre systems manage and control land ownership with diagrams, plans, maps, and charts to insure reliable facts about a specific land [4]. This information are the base attributes of GIS-based Cadaster Land Information Systems [30].

Land Information Systems use cadastral maps to show boundaries and ownership of land pieces and detailed information such as identifying numbers, district names, structure, boundaries, and the area size [13]. Most countries use outdated cadastral management systems, such as the legacy systems explained above, to manage their land ownership. It is important now more than ever to invest in improving these systems of land ownership to be able to fully trust, manage, and exchange the information regarding land ownership among participants such as owners and legal authorities.

Blockchain can be used to manage real estate transactions. The transaction will be recorded into the ledger with the exchange of a Bitcoin or Ethereum cryptocurrency between two parties. It can also record the details of the land or property transfer within the legal, tax, and government authorities' systems for confirmation and validation of the transaction. In the supply chain industry, business leaders could use blockchain to record and monitor the location of any product. For instance, to record where, when, and how a shipment of fresh coffee was transferred from the warehouse, to the supplier, and finally, to the local store.

As such, the GeoBlockchain can answer questions such as where, why, and how; for example, how might a land transaction or a shipping container take place as a trust-trade exchange between different owners and how might that be verified by legal and private authorities? That brings us to the idea of "trust-free", the same approach as cryptocurrency's legal regulations [8].

How is that different from a typical traditional land ownership and supply chain transaction systems, and how might blockchain and geospatial technologies work together to answer the where and why [7, 28, 32]? By incorporating rules and roles into the blockchain, you can provide a trust context based on location to the tabular transaction to answer and explore the "trust" of a transaction [2].

\section{Fundamentals - Theoretical Background}

According to Peffers et al. and Hevner et al., the DSR methodology is a design method to build and evaluate an artifact by using existing kernel theories, 
design principles, design guidelines and providing contribution to practice and knowledge $[1,18]$. This study utilized Peffers 6-step process to guide the research activities which include: (1) identify the problem and its motivation, (2) define objectives and components of the solution, (3) design the artifact and its development, (4) demonstrate usage of the artifact, (5) evaluate the artifact by using technological performance and socio-technical assessments, and (6) communicate the findings and contribute to the knowledgebase [18] (Figure 1). This process is an iterative loop that can be modified and evaluated in each step by having users and stakeholders test and evaluate each step (Figure 3). The goal is to solicit feedback from users and stakeholders in a manner that constantly improves the artifact and at the same time, provides relevance in practice, and rigor in knowledge [1].

This study utilized Q Methodology to solicit participant viewpoints regarding blockchain and geospatial technology to evaluate the industry's implementation and integration perspectives. According to Dennis et. Al, "The main principle of the $\mathrm{Q}$
Methodology is to enable researchers to discover and learn about human subjectivity" [10]. Also, in a Q study, "each factor demonstrates a key perspective that exists within the group of study participants". [3] However, Brown et. al, described Q Methodology as a way to "enable the analysis of these viewpoints holistically, employing a deep quantitative and qualitative investigation", [3, 7, 28, 32].

\subsection{The research questions were defined as:}

- Q1: What are the main attributes for a GeoBlockchain enterprise solution framework?

- Q2: What are the main criteria used for a GeoBlockchain enterprise solution?

- Q3: What is the importance of roles and rules, in order to build trust among participants?

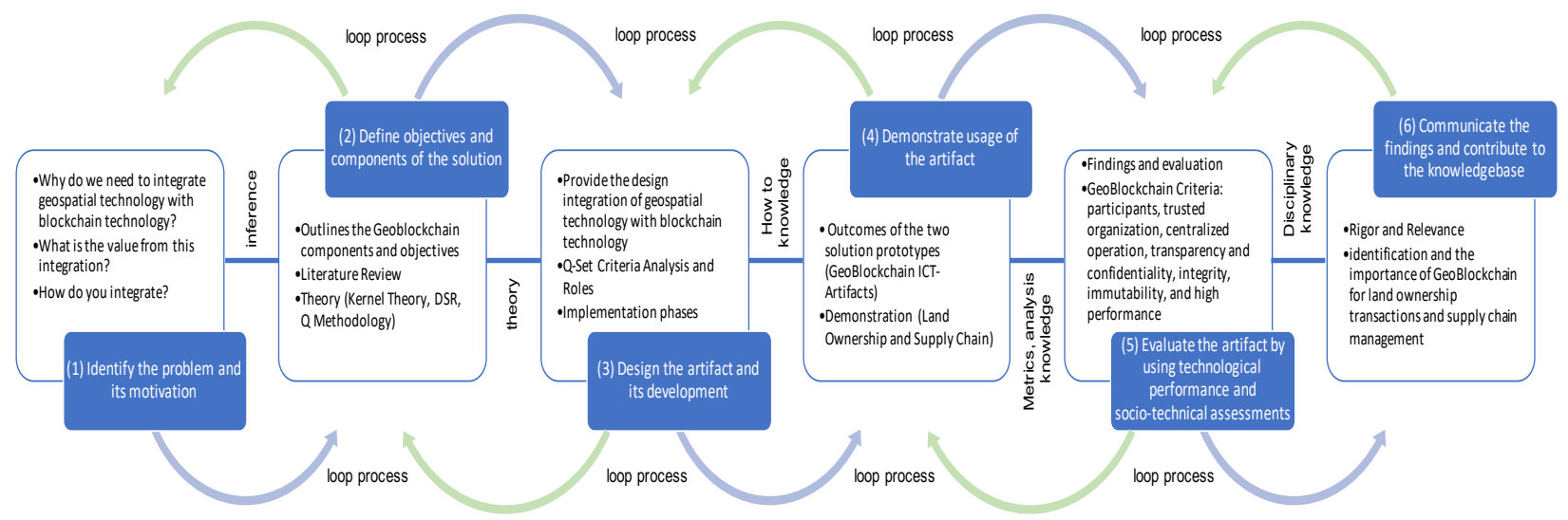

Figure 1. Applied six-step process of Design Science Research

\section{Methodology}

The problem and motivation $\left(1^{\text {st }}\right.$ step of Peffers et al.) is discussed in the Introduction Section. The Literature Review ( $2^{\text {nd }}$ step) outlines the Geoblockchain components and objectives. Here, Section 4.1 and Section 4.2. $\left(3^{\text {rd }}\right.$ step) provide the design integration of geospatial technology with blockchain technology; Section 4.3 discusses the implementation phases; Section 5.1 and Section 5.2. discusses outcomes ( $4^{\text {th }}$ step) of the two solution prototypes; the demonstration is provided in Section 5.3.; findings and evaluation $\left(5^{\text {th }}\right.$ step) are explained in Section 6; and rigor and relevance
( $6^{\text {th }}$ step) are discussed in the Discission and Conclusion Sections.

Since the Q-method is a technique that is specialized for the analysis of peoples' subjective beliefs [7, 32], we used Q-Set for ranking and sorting specific statements, to identify the attributes and criteria for the GeoBlockchain land ownership and supply chain use cases. 40 semi-structured interviews were conducted drawing on participants from a land ownership government organization and a private supply chain organization; 20 interviews for each organization. Field notes and reports were collected from each organization to validate the responses using triangulation methods. This activity used the CAQDAs 
software to analyze the semi-structured interviews, field notes, and reports by using the Strauss and Corbin coding technique [26]. The Q sort process was used to analyze and factor the participants responses from existing surveys within the organization. A statistical quantitative factor analysis technique was used for data reduction and to summarize the variables for the $\mathrm{Q}$ Sorting.

As mentioned, blockchain and geospatial are the main technologies that could connect the front-end and back-end components. Specifically, Hyperledger Fabric, an IBM blockchain cloud service provider, was the primary high-performance consensus protocol for the blockchain component [19]. While ArcGIS Enterprise provides the geospatial capabilities and is also used as the cloud technology integration platform.

\subsection{First Task - Identify GeoBlockchain Components}

The conceptual diagram (Figure 2) provides a highlevel, conceptual overview of how the Hyperledger Fabric blockchain provider is integrated with ArcGIS Enterprise. Through that combination, the blockchain provider provides encrypted and trusted information to the geospatial secured cloud that manages the multiple participants that are involved in land ownership and supply chains [6].

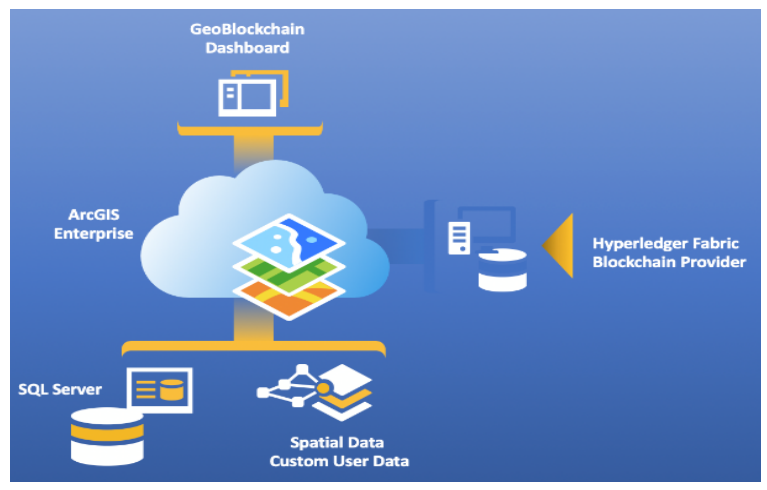

Figure 2. GeoBlockchain Conceptual Diagram

Conversely, ArcGIS Enterprise leverages the spatial information from Hyperledger Fabric blockchain, and transforms, analyzes, and visualizes the data from both the blockchain and geospatial clouds, and presents that information in a GeoBlockchain dashboard. Here, blockchain data is defined as standardized transactions, legal contracts, private or personal information, and financial information from multiple participants, and in this case, land ownership and supply chain information [21].

\subsection{Second Task - Q-Set Criteria Analysis}

Seven Q-Set criteria were defined for the two GeoBlockchain enterprise solution-prototypes based on the Q methodology fundamentals (Table 1). Participants are power users from different entities, departments, and divisions that could participate in a GeoBlockchain scenario, specifically in a land ownership and supply chain examples. Trusted Organizations are the authorities that could control the policies, rules, and roles between the participants. Centralized operation is unique for each participant. All participants could share secured information which was made transparent through the Geoblockchain. Any transaction data that is written cannot be manipulated as a result to have integrity and immutability. Lastly, the highperformance criterion is important for system scalability and system performance due to the huge amount of data that is recorded from spatial and non-spatial transactions.

Table 1. Q-Set Criteria

\begin{tabular}{|l|l|l|}
\hline N/A & Q-Set Criteria & Description \\
\hline 1 & Participants & $\begin{array}{l}\text { Multiple organizations } \\
\text { participated in the land } \\
\text { ownership and supply chain } \\
\text { examples }\end{array}$ \\
\hline 2 & $\begin{array}{l}\text { Trusted } \\
\text { Organization }\end{array}$ & $\begin{array}{l}\text { The main authority in the } \\
\text { blockchain that controls policies, } \\
\text { rules, and roles }\end{array}$ \\
\hline 3 & $\begin{array}{l}\text { Centralized } \\
\text { Operation }\end{array}$ & $\begin{array}{l}\text { Every participant controls and } \\
\text { manages their transaction } \\
\text { information from the } \\
\text { GeoBlockchain }\end{array}$ \\
\hline 4 & $\begin{array}{l}\text { Transparency } \\
\text { and } \\
\text { confidentiality }\end{array}$ & $\begin{array}{l}\text { All participants could share } \\
\text { encrypted information through } \\
\text { the GeoBlockchain }\end{array}$ \\
\hline 5 & Integrity & $\begin{array}{l}\text { All transactions are written into } \\
\text { the blockchain history for } \\
\text { provenance }\end{array}$ \\
\hline 6 & Immutability & $\begin{array}{l}\text { Data on the GeoBlockchain } \\
\text { cannot be changed easily or } \\
\text { deleted }\end{array}$ \\
\hline 7 & $\begin{array}{l}\text { High } \\
\text { Performance }\end{array}$ & $\begin{array}{l}\text { System scalability and system } \\
\text { behavior from big } \\
\text { GeoBlockchain datasets either } \\
\text { text (blockchain) or spatial } \\
\text { (geospatial) }\end{array}$ \\
\hline
\end{tabular}

\subsection{Third Task - GeoBlockchain ICT Artifacts}

For the third task, the artifacts were created with the integration of Hyperledger Fabric Cloud and ArcGIS Enterprise. We identified all GeoBlockchain participant roles for both scenarios (Tables 2 and 3). Both 
GeoBlockchain examples used the same number of participant roles for better comparison and evaluation.

The outcome of these activities was a cloud-based GeoBlockchain Web Dashboard that participants used during the land ownership and supply chain scenarios. Different roles with specific profiles were leveraged through those scenarios, and all transactions (spatial and not spatial) were recorded into the GeoBlockchain.

Table 2: Land Ownership Roles

\begin{tabular}{|l|l|}
\hline \multicolumn{2}{|c|}{ Land Ownership Example } \\
\hline Participants & Responsibilities \\
\hline $\begin{array}{l}\text { GeoBlockchain- } \\
\text { Administrator }\end{array}$ & $\begin{array}{l}\text { Administrator has full privileges to } \\
\text { Hyperledger Fabric and ArcGIS } \\
\text { Enterprise }\end{array}$ \\
\hline $\begin{array}{l}\text { GeoBlockchain- } \\
\text { Seller }\end{array}$ & $\begin{array}{l}\text { Participant that is added to } \\
\text { GeoBlockchain with controlled } \\
\text { roles only for "Seller" Group }\end{array}$ \\
\hline $\begin{array}{l}\text { GeoBlockchain- } \\
\text { Legal Authority }\end{array}$ & $\begin{array}{l}\text { Participant that is added to } \\
\text { GeoBlockchain with controlled } \\
\text { roles only for "Legal Authority" } \\
\text { Group }\end{array}$ \\
\hline $\begin{array}{l}\text { GeoBlockchain- } \\
\text { Land Owners }\end{array}$ & $\begin{array}{l}\text { Participant that is added to } \\
\text { GeoBlockchain with controlled } \\
\text { roles only for "Land Owners" } \\
\text { Group }\end{array}$ \\
\hline $\begin{array}{l}\text { GeoBlockchain- } \\
\text { Customers }\end{array}$ & $\begin{array}{l}\text { Participant that is added to } \\
\text { GeoBlockchain with controlled } \\
\text { roles only for "Ship" Group }\end{array}$ \\
\hline $\begin{array}{l}\text { GeoBlockchain- } \\
\text { Stakeholders }\end{array}$ & $\begin{array}{l}\text { User that is added to Blockchain } \\
\text { with controlled roles only for } \\
\text { "Stakeholders" Group }\end{array}$ \\
\hline
\end{tabular}

Table 3: Supply Chain Roles

\begin{tabular}{|l|l|}
\hline \multicolumn{2}{|c|}{ Supply Chain Example } \\
\hline Participants & Responsibilities \\
\hline $\begin{array}{l}\text { GeoBlockchain- } \\
\text { Administrator }\end{array}$ & $\begin{array}{l}\text { Administrator has full privileges to } \\
\text { Hyperledger Fabric and ArcGIS } \\
\text { Enterprise }\end{array}$ \\
\hline $\begin{array}{l}\text { GeoBlockchain- } \\
\text { Supplier }\end{array}$ & $\begin{array}{l}\text { Participant that is added to } \\
\text { GeoBlockchain with controlled } \\
\text { roles only for "Supplier" Group }\end{array}$ \\
\hline $\begin{array}{l}\text { GeoBlockchain- } \\
\text { Port }\end{array}$ & $\begin{array}{l}\text { Participant that is added to } \\
\text { GeoBlockchain with controlled } \\
\text { roles only for "Port" Group }\end{array}$ \\
\hline $\begin{array}{l}\text { GeoBlockchain- } \\
\text { Distribution Center }\end{array}$ & $\begin{array}{l}\text { Participant that is added to } \\
\text { GeoBlockchain with controlled } \\
\text { roles only for "Distribution Center" } \\
\text { Group }\end{array}$ \\
\hline $\begin{array}{l}\text { GeoBlockchain- } \\
\text { Shipping }\end{array}$ & $\begin{array}{l}\text { Participant that is added to } \\
\text { GeoBlockchain with controlled } \\
\text { roles only for "Ship" Group }\end{array}$ \\
\hline $\begin{array}{l}\text { GeoBlockchain- } \\
\text { Trucking }\end{array}$ & $\begin{array}{l}\text { User that is added to Blockchain } \\
\text { with controlled roles only for } \\
\text { "Trucking" Group }\end{array}$ \\
\hline
\end{tabular}

Incorporating usability and user engagement in this process is very important. Users and stakeholders were engaged during the design, development and evaluation phases until the final production solution was achieved (Figure 3).

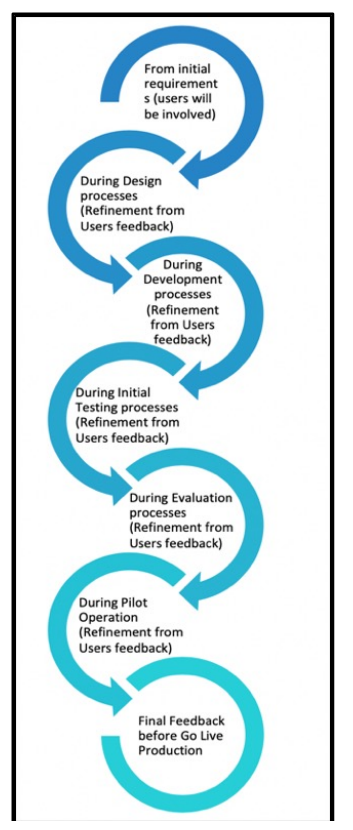

Figure 3. Users and Stakeholders Involvement

\section{Implementation Phases}

There were three main implementation phases for the creation of the two GeoBlockchain prototypes.

Phase-1 was the design and development of the back-end components where the Hyperledger Fabric blockchain API service was utilized along with the ArcGIS Enterprise API rest service. Phase-2 was the creation of various coding artifacts that connect the blockchain API services and geospatial API services resulting in the creation of the GeoBlockchain.

Finally, Phase- 3 involved the creation of the frontend; an interactive dashboard that visualizes the GeoBlockchain results in a web-based application that includes various widgets and map-based output. This dashboard also allows the participants to interact with the two main systems, and to add and edit land ownership transactions.

\subsection{Architecture Diagram}

The GeoBlockchain architecture outlines these three main phases with four main important processes; Configure, Collaborate, Blockchain, and Visualize (Figure 4). 


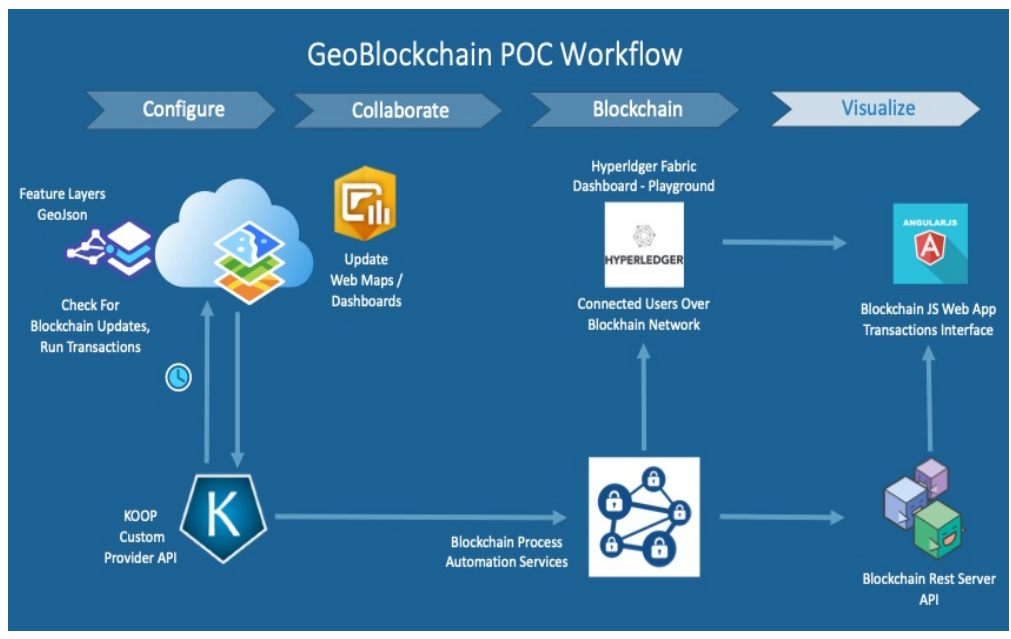

Figure 4. GeoBlockchain Architecture Design

\subsection{GeoBlockchain Workflow Processes}

The Configure process contains the implementation and integration of Hyperledger Fabric API's with ArcGIS Enterprise API's. Hyperledger Fabric API will communicate with ArcGIS Enterprise API through a custom API. In this case, the KOOP API was utilized, a compatible provider for ArcGIS Enterprise. The purpose of a custom KOOP REST API is to translate the data record into a geospatial format such as the GeoJson format. This provides the capability to geolocate all the raw location data from the blockchain, for example, latitude and longitude coordinates into GeoJson points.

ArcGIS Enterprise datasets include spatial information; for example, spatial points, lines, and polygons which is necessary for a land ownership use case as land datasets include polygons, lines, and points. The Collaborate process uses this custom API with the main goal to share trusted and valid information between blockchain and geospatial platforms. In addition, the two technologies create and update records, either into the ArcGIS Enterprise or into Hyperledger Fabric.

The Blockchain process provides the technological foundation for all participants involved in a land ownership and supply chain transaction. Each participant has specific roles and rules assigned within the blockchain. This process provides each participant the ability to agree or not agree with information that is to be recorded into the blockchain ledger. For instance, financial information such as cost and price, legal information such as land titles and land property history, and spatial information such as parcel area and parcel measurements. Lastly, the Visualize process provides a map dashboard component that is the front-end interaction between the participants for land ownership or supply chain transactions. For this study, the two GeoBlockchain web map applications were created to demonstrate this capability.

\subsection{GeoBlockchain ICT- Artifacts Outcomes}

The first artifact of this study was the instantiation of a GeoBlockchain for land ownership transactions and a related dashboard. Through this prototype, participants (landowners, customers, and other stakeholders) can exchange (buy or sell) land through the blockchain component, and instantly view the results through the GIS component.

As displayed in Figure 5, a single-family property with ID 2001, and USD price of $\$ 750,000$, was transferred from Owner A to Owner B. This prototype dashboard visualizes the property locations on a map and can answer "where" the transaction occurred and "why" the event happened based on historic transaction events. The power of geospatial technology is applied to the dashboard with the addition of specialized widgets (Figure 6) that display statistics from the blockchain and geospatial technologies. The second artifact of this study is a GeoBlockchain supply chain dashboard web application (Figure 7).

This research indicates that blockchain technology can be integrated with geospatial technology, resulting in the GeoBlockchain. Both GeoBlockchain web application artifacts allow participants and stakeholders to track overall land ownership and supply chains and various statistics such as the average price at the selected geographic location and/or examine the individual land price using geospatial and blockchain statistical tools [22]. 


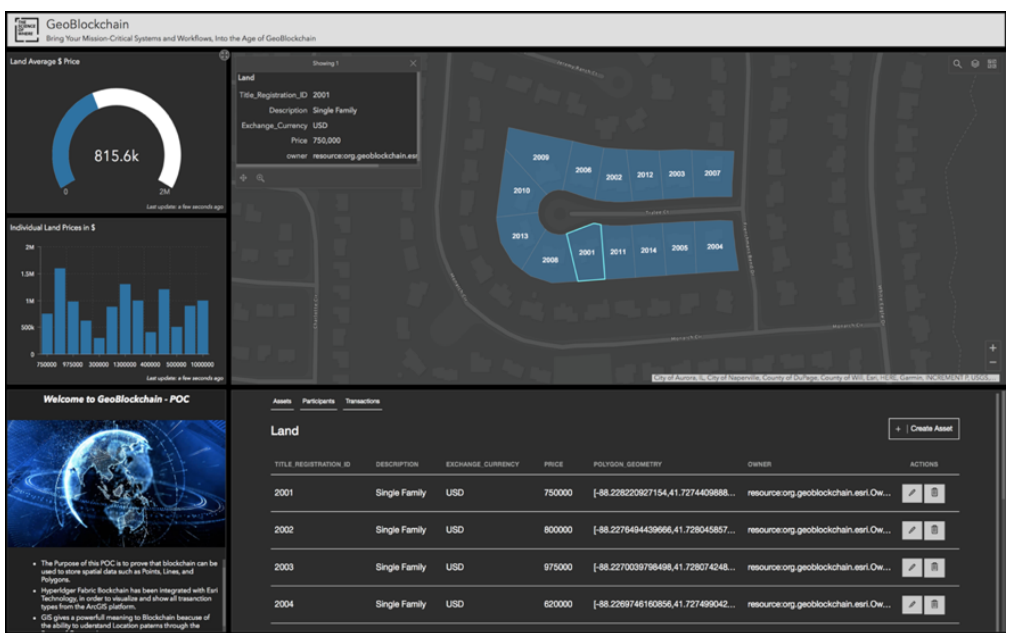

Figure 5. GeoBlockchain Dashboard - Land Ownership

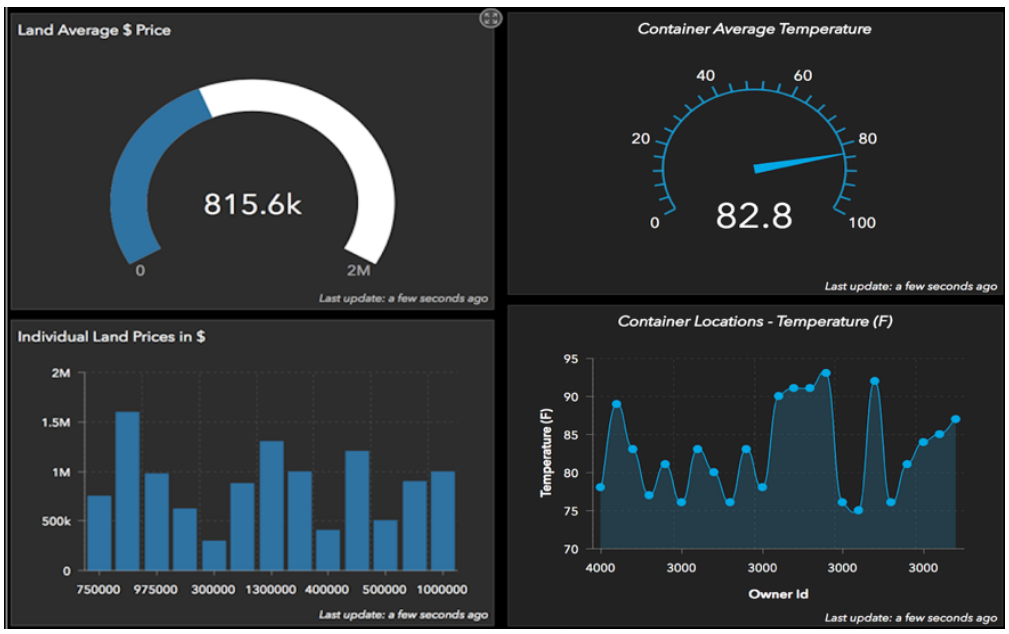

Figure 6. GeoBlockchain Widgets

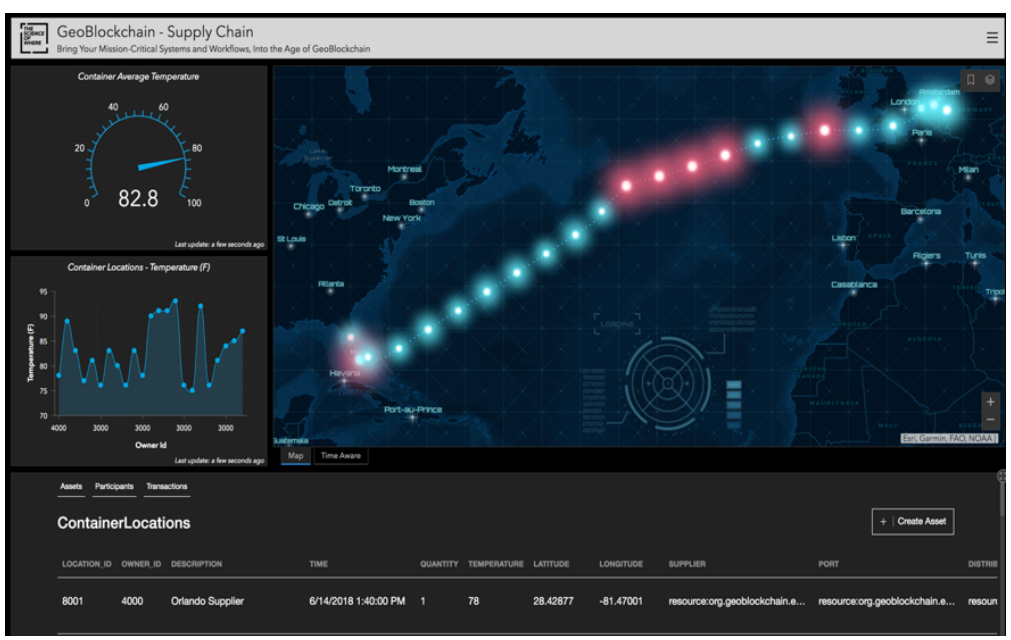

Figure 7. GeoBlockchain Dashboard - Supply Chain 


\section{Findings and Evaluation}

The seven criteria defined in the Q-Methodology study (participants, trusted organization, centralized operation, transparency and confidentiality, integrity, immutability, and high performance) were examined and generalized against the two GeoBlockchain web dashboard prototypes. All the participants had been assigned specific rules and roles in the GeoBlockchain workflow processes. The purpose of the unique roles and rules was to provide trust and transparency through the land ownership and supply chain workflow processes.

Trusted Organizations, in this case, are private and legal authorities who orchestrate and manage the interaction between participants in the GeoBlockchain and for better interaction with matters related with tax regulations and legal concerns $[11,20]$. The orchestrators were responsible for the approved rules, roles, and the smooth transaction between participants in order to establish transparency and confidentiality [24]. The goal was to have integrity through the process and between the participants.

The Immutability criterion of the GeoBlockchain provided the ability to answer questions related to the "where and why" questions. The "where" is the location of the land ownership transaction such as the real geographic representation of the property parcel. The "why" is the recorded history of the of all the approved land ownership transactions into the GeoBlockchain.

Lastly, the Performance criterion is examined based on the total time for the land ownership transaction to be completed. The GeoBlockchain system was developed in the cloud; here available resources can be modified and adjusted based on systems transaction load. In addition, the entire land ownership process is faster than the traditional land ownership transaction process as most of the mediators are not needed and the process is more automated. The time needed from the beginning to the end of the land ownership transaction would be less as it requires less face-to-face interactions, less bureaucracy, and wait times.

The seven Q-set criteria, for the two artifacts, were examined in relation to the three research questions. The results were evaluated with unique measurement values such as required and not required. The evaluation methodology is motivated from recent study "Evaluating Suitability of Applying Blockchain", [29].

The resultant findings (Table 4) support the evaluation of the criteria and the research questions.
Table 4. GeoBlockchain Criteria Evaluation

\begin{tabular}{|l|l|l|l|}
\hline \multirow{2}{*}{$\begin{array}{l}\text { GeoBlockchain } \\
\text { Criteria (Q-set) } \\
\text { Evaluation }\end{array}$} & \multicolumn{3}{|l|}{$\begin{array}{l}\text { GeoBlockchain } \\
\text { (Hyperledger-Fabric/ArcGIS }\end{array}$} \\
\cline { 2 - 4 } Enterprise) & Q1 & Q2 & Q3 \\
\hline Participants & Req. & Req. & Req. \\
\hline $\begin{array}{l}\text { Trusted } \\
\text { Organization }\end{array}$ & Req. & Req. & Req. \\
\hline $\begin{array}{l}\text { Centralized } \\
\text { Operation }\end{array}$ & Req. & Req. & Req. \\
\hline $\begin{array}{l}\text { Transparency and } \\
\text { Confidentiality }\end{array}$ & Req. & Req. & Req. \\
\hline Integrity & Req. & Req. & Req. \\
\hline Immutability & Non- Req. & Req. & Non- Req. \\
\hline $\begin{array}{l}\text { High } \\
\text { Performance }\end{array}$ & Req. & Req. & Non- Req. \\
\hline
\end{tabular}

For the first research question (Q1), only the organizations participating in a transaction will have knowledge about it, whereas the others will not be able to access it; as a result, data immutability is not fully applied and is not required for the GeoBlockchain. Only participants, trusted organizations, data transparency and confidentiality, data integrity, and highperformance criteria are required for the main attributes of GeoBlockchain.

The second research question (Q2) is the only one that entirely encounters all the blockchain criteria (participants, trusted organizations, data transparency and confidentiality, data integrity, and highperformance) as GeoBlockchain attributes. However, generic attributes and custom attributes are required for GeoBlockchain use cases. The main reason is that every single use case is a unique study, and flexibility is needed for generalization.

Lastly, the third research question (Q3) encompasses the GeoBlockchain criteria as seen in Tables 2 and 3. For instance, the centralized operation is required for trust between participants. However, data immutability and high performance are not obligatory either for participants' or trusted organizations.

\section{Discussion}

The main limitations of the current study include: (1) further iterations are required to improve this prototype, (2) a production enterprise environment is required for real-world testing, and related to this, (3) the prototype needs to be tested with a larger data set, and finally, (4) a formal end-user assessment needs to be conducted. Upcoming plans include: (1) completing the next generation solution prototype artifact; (2) 
completing multiple iterations to improve the GeoBlockchain design; (3) improving the suitability evaluation analysis; (4) researching other types of blockchains such as hybrid blockchains for suitability and relevance; and (5) completing the pre-test and posttest evaluation in order to assess the GeoBlockchain framework.

\section{Conclusion}

The outcomes of this research are the identification and the importance of GeoBlockchain for land ownership transactions and supply chain management. As demonstrated, this can be achieved by leveraging existing blockchain and geospatial frameworks and utilizing the identified Q-set criteria from the QMethodology approach.

The two working prototypes demonstrate that blockchain technology can be integrated with geospatial technology resulting in a GeoBlockchain. The three tasks, implementation phases, and workflow processes answer the first and second research questions and provide the main components and criteria for GeoBlockchain land ownership and supply chain examples. For the third research question, it is argued that the value that blockchain makes available to geospatial technology is its transparency, real-time, security, cost-effective recording, immutability, and storage of trusted data information. On the other hand, geospatial technology provides the power of location to the blockchain.

The GeoBlockchain dashboard is a prototype system designed to record, analyze, share, and visualize a variety of blockchain and geographical data. The result is a concept that should impact society by simplifying the supply chain management and land ownership transaction experience for organizations, citizens, and governments. This presents an opportunity for supply chain and land ownership stakeholders to take advantage of these new blockchain-based datasets and access that data using their geospatial system to see and understand their world like never before.

Private blockchains such as Hyperledger Fabric and geospatial technologies such as ArcGIS could potentially be used for any GeoBlockchain use case. This research will continue with enhancements and refinements through development and testing which will be demonstrated through next generation releases.

\section{Acknowledgements}

We want to acknowledge the Advanced GIS Lab at Claremont Graduate University; Environmental Systems Research Institute, Inc.; several Blockchain consortiums; and the various stakeholders that collaborated with this study.

\section{References}

[1] A.R. Hevner, S.T. March, J. Park, S. Ram, design science in information systems research, MIS Quarterly 28 (2004) 75, https://doi.org/10.2307/25148625.

[2] Brambilla, G., Amoretti, M., \& Zanichelli, F. (2016). Using Blockchain for Peer-to-Peer Proof-of-Location. Retrieved from http://arxiv.org/abs/1607.00174

[3] Brown, S. R. (1996). Q Methodology and Qualitative Research. Qualitative Health Research, 6(4), 561-567. https://doi.org/10.1177/104973239600600408

[4] Bureau of Land Management, "Programs: Lands and Realty: Cadastral Survey," Aug. 17, 2016. https://www.blm.gov/programs/lands-andrealty/cadastral-survey (accessed Apr. 25, 2020).

[5] Coignard, J., Munsing, E., MacDonald, J., Mather, J., \& Ieee. (2018). Co-simulation Framework for Blockchain Based Market Designs and Grid Simulations. In 2018 Ieee Power \& Energy Society General Meeting. New York: Ieee.

[6] Crompton, S., \& Jensen, J. (2018). Towards a Secure and GDPR-compliant Fog-to- Cloud Platform. In A. Sill \& J. Spillner (Eds.), 2018 Ieee/Acm International Conference on Utility and Cloud Computing Companion (pp. 296301). New York: Ieee.

[7] Croxson, A., Sharma, R., \& Wingreen, S. (2019). Making Sense of Blockchain in Food Supply-Chains 2 Background Review. 1-11.

[8] Cvetkova, I. (2018). Cryptocurrencies Legal Regulation. Brics Law Journal, 5(2), 128-153. doi:10.21684/24122343-2018-5-2-128-153

[9] Dasu, T., Kanza, Y., \& Srivastava, D. (2018). Unchain Your Blockchain. Proc. Symposium on Foundations and Applications of Blockchain, 1(March), 16-23.

[10] Dennis, K. E. (1986). Q methodology: Relevance and application to nursing research. Advances in Nursing Science, 8(3), 6-17. https://doi.org/10.1097/00012272198604000-00003

[11] Dimitropoulou, C., Govind, S., \& Turcan, L. (2018). Applying Modern, Disruptive Technologies to Improve the Effectiveness of Tax Treaty Dispute Resolution: Part 2. Intertax, 46(12), 960-970.

[12] Garcia-Teruel, R.M. (2020). "Legal challenges and opportunities of blockchain technology in the real estate sector", Journal of Property, Planning and Environmental 
Law, Vol. 12 No. 2, pp. 129-145. https://doi.org/10.1108/JPPEL-07-2019-0039.

[13] J. D. McLaughlin and I. P. Williamson, "Trends in Land Registration," The Canadian Surveyor, vol. 39, no. 2, pp. 95-108, Jun. 1985, doi: 10.1139/tcs-1985-0012.

[14] J. Patel, "Exploring Enterprise Resource Planning (ERP) And Geographic Information System (GIS) Integration," Dec. 2013.

[15] Kamel Boulos, M. N., Wilson, J. T., \& Clauson, K. A. (2018). Geospatial blockchain: promises, challenges, and scenarios in health and healthcare. International Journal of Health Geographics, 17(1), 25. https://doi.org/10.1186/s12942-018-0144-x

[16] K. Clarke, "Advances in Geographic Information Systems," Computers, Environment and Urban Systems, vol. 10, pp. 175-184, Dec. 1986, doi: 10.1016/01989715(86)90006-2.

[17] Koh, L., Dolgui, A., Sarkis, J. (2020). Blockchain in transport and logistics - paradigms and transitions, International Journal of Production Research, 58:7, 20542062, https://doi.org/10.1080/00207543.2020.1736428.

[18] K. Peffers, T. Tuunanen, M.A. Rothenberger, S. Chatterjee, A design science research methodology for information systems research, Journal of Management Information Systems $24 \quad$ (2007) 45-77, https://doi.org/10.2753/MIS0742-1222240302.

[19] Li, K. J., Li, H., Hou, H. X., Li, K. D., Chen, Y. L., \& Ieee. (2017). Proof of Vote: A High-Performance Consensus Protocol Based on Vote Mechanism \& Consortium Blockchain. New York: Ieee.

[20] Lin, Y.-P., Petway, J., Lien, W.-Y., \& Settele, J. (2018). Blockchain with Artificial Intelligence to Efficiently Manage Water Use under Climate Change. Environments, 5(3), 34 https://doi.org/10.3390/environments5030034

[21] Lynch, S. (2018). OpenLitterMap.com - Open Data on Plastic Pollution with Blockchain Rewards (Littercoin). Open Geospatial Data, Software and Standards, 3(1). https://doi.org/10.1186/s40965-018-0050-y

[22] McGinn, D., McIlwraith, D., \& Guo, Y. (2018). Towards open data blockchain analytics: a Bitcoin perspective. Royal Society Open Science, 5(8), 14. doi:10.1098/rsos.180298

[23] Montes, G. A., \& Goertzel, B. (2019). Distributed, decentralized, and democratized artificial intelligence. Technological Forecasting and Social Change, 141, 354358. doi:10.1016/j.techfore.2018.11.010
[24] Pahl, C., El Ioini, N., Helmer, S., Lee, B., \& Ieee. (2018). An Architecture Pattern for Trusted Orchestration in IoT Edge Clouds. New York: Ieee.

[25] P. F. Dale and J. D. McLaughlin, "Land information management: an introduction with special reference to cadastral problems in Third World countries," 1988, Accessed: Apr. 25, 2020. [Online]. Available: http://agris.fao.org/agrissearch/search.do?recordID=XF2015016826.

[26] R. LaRossa, "Grounded theory methods and qualitative family research," J. Marriage Fam., vol. 67, no. 4, pp. 837-857, 2005.

[27] Ryskeldiev, B., Ochiai, Y., Cohen, M., \& Herder, J. (2018). Distributed metaverse: Creating decentralized blockchain-based model for peer-To-peer sharing of virtual spaces for mixed reality applications. ACM International Conference Proceeding Series. https://doi.org/10.1145/3174910.3174952

[28] Sharma, R. S., Wingreen, S., Kshetri, N., \& Hewa, T. M. (2019). Design principles for use cases of blockchain in food supply chains. 25th Americas Conference on Information Systems, AMCIS 2019, 1-10. Retrieved from

https://aisel.aisnet.org/cgi/viewcontent.cgi?article $=1300$ \& context $=$ amcis 2019

[29] S. K. Lo, X. Xu, Y. K. Chiam and Q. Lu, "Evaluating Suitability of Applying Blockchain," 2017 22nd International Conference on Engineering of Complex Computer Systems (ICECCS), Fukuoka, 2017, pp. 158161, doi: 10.1109/ICECCS.2017.26.

[30] T. Wade and S. Sommer, A to Z GIS: An Illustrated Dictionary of Geographic Information Systems. ESRI Press, 2006.

[31] V. Maliene, V. Grigonis, V. Palevičius, and S. Griffiths, "Geographic information system: Old principles with new capabilities," Urban Design International, vol. 16, Mar. 2011, doi: 10.1057/udi.2010.25.

[32] Wingreen, S., Sharma, R., jahanbin, pouyan, Wingreen, S., \& Sharma, R. (2019). a Blockchain Traceability Information System for Trust Improvement in Agricultural Supply Chain. Research-in-Progress Papers, 5-15. Retrieved from https://aisel.aisnet.org/ecis2019_rip/10

[33] Yuan, Y., \& Wang, F. Y. (2016). Towards blockchainbased intelligent transportation systems. IEEE Conference on Intelligent Transportation Systems, Proceedings, ITSC, (October 2017), 2663-2668. https://doi.org/10.1109/ITSC.2016.779598 